\title{
Cracking in cement paste induced by autogenous shrinkage
}

\author{
Pietro Lura · Ole Mejlhede Jensen · Jason Weiss
}

Received: 9 June 2008/Accepted: 14 October 2008/Published online: 23 October 2008

(C) RILEM 2008

\begin{abstract}
Detection and quantification of microcracks caused by restrained autogenous shrinkage in high-performance concrete is a difficult task. Available techniques either lack the required resolution or may produce additional cracks that are indistinguishable from the original ones. A recently developed technique allows identification of microcracks while avoiding artefacts induced by unwanted restraint, drying, or temperature variations during sample preparation. Small cylindrical samples of cement paste are cast with steel rods of different diameters in their centre. The rods restrain the autogenous shrinkage of the paste and may cause crack formation. The crack pattern is identified by impregnation with gallium and analyzed by optical and scanning electron microscopy. In this study, a non-linear numerical analysis of the samples was performed. Autogenous strain, elastic modulus, fracture energy, and creep as a function of hydration time were used as inputs in the analysis. The experimental results and the
\end{abstract}

P. Lura $(\bowtie)$

Empa Swiss Federal Laboratories for Materials Testing

\& Research, CH-8600, Dubendorf, Switzerland

e-mail: pietro.lura@empa.ch

O. M. Jensen

Department of Civil Engineering, Technical University

of Denmark, DK-2800, Lyngby, Denmark

J. Weiss

School of Civil Engineering, Purdue University,

West Lafayette, IN, USA numerical analysis showed that samples with larger steel rods had the highest probability of developing microcracks. In addition, the pattern and the width of the observed microcracks showed good agreement with the simulation results.

Keywords Autogenous strain - Shrinkage · Microcracking · Creep

\section{Introduction}

The cement paste of a modern, high-performance concrete typically shows low porosity and a discontinuous capillary pore structure. This is often obtained by keeping a low water to cement ratio (w/c) and by adding silica fume. While modern concretes can possess some advantageous properties compared with traditional concrete in terms of good workability, high strength from early ages, low permeability, and improved durability, they may also exhibit unwanted behaviour such as autogenous strain. Autogenous strain is the self-created bulk strain of cement paste, mortar or concrete during hardening at constant temperature. In conventional concrete, autogenous shrinkage strain is generally negligible, whereas in high-performance concrete it may be considerable [1]. Restraint of the autogenous strain by aggregates or adjoining structural members may result in formation of micro and macro cracks that impair strength, durability and aesthetics [2-5]. 
Recently, there has been interest in analyzing the stress development and microcracking that occurs when concrete is considered as a two or three phase material composed of aggregates, cement paste and interface zone. While several studies have examined the behaviour under an externally applied load [6, 7], other recent studies have focused on the mismatch in deformations that occurs when the cement paste deforms and the aggregate does not. Dela [8] investigated the stress development around a spherical ceramic aggregate, while Pease et al. [9] examined the stress development and cracking behaviour around a cylindrical aggregate. More realistic microstructures have also been simulated. For example Garboczi [10] simulated the stress development that occurs around an expanding aggregate in a fixed paste, while Moon et al. [11, 12] examined the cracking behaviour when the aggregate remains constant in size and the paste shrinks. While these works all provide valuable contributions to the understanding of the mechanisms involved, the problem remains very complex due to the time dependent nature of the cement paste as well as the difficulty in measuring local stress and cracking simultaneously in an undisturbed sample.

A central element in this study is the technique used to detect microcracks induced by autogenous shrinkage in cement paste. It requires special precautions to maintain the sample in autogenous conditions throughout the whole preparation procedure, i.e., sealed, at constant temperature, and without external restraint. A technique based on intruding the microcracks with liquid gallium allows fast and controllable impregnation of cracks in the cement paste [13, 14]. After solidification of the gallium, the crack pattern due to autogenous shrinkage is frozen and can be analyzed with a number of techniques, including optical microscopy, electron probe micro analysis (EPMA), and scanning electron microscopy (SEM).

Examples of microcrack detection in cement paste and a first numerical analysis of the results have been described in detail in previous papers [15-17], and are summarized in the following. In this paper, a numerical analysis of the samples is performed, imposing on the cement paste a time-dependent shrinkage and considering mechanical properties evolving with hydration, creep and cracking. The simulation results are subsequently compared to the actual measurements.

\section{Materials and methods}

\subsection{Cement paste}

A high-performance cement paste with w/c 0.3 and $20 \%$ silica fume addition was used in this study. The cement was a Danish white Portland cement by Aalborg Portland. Further details can be found in $[14,15]$.

\subsection{Linear autogenous strain}

Linear autogenous strain of cement pastes was measured at $32 \pm 0.1^{\circ} \mathrm{C}$ by a specially developed measuring technique, where the cement paste is encapsulated in thin, corrugated polyethylene moulds of length about $300 \mathrm{~mm}$ and diameter $30 \mathrm{~mm}$. The technique ensures insignificant restraint of the hardening cement paste and permits measurements to start right after water addition. More details on the measuring technique can be found in [18].

\subsection{Elastic modulus and facture energy}

The elastic modulus and fracture energy of the cement paste were derived from the literature [8], where details about the measurements are explained. It should be noted that in the cement paste measured in [8], not only the same mixture composition, but also the same cement and silica fume were used as in the present study. However, the measurements in [8] were performed at $20^{\circ} \mathrm{C}$. In order to use these material properties for simulating stress development and cracking at $32^{\circ} \mathrm{C}$, a maturity transformation of the measured material properties was performed [19, 20].

\subsection{Crack detection}

In the present study, microcrack formation due to autogenous shrinkage was studied by means of a simplified, 2-dimensional model. Cement pastes samples were studied with $1.5,3$, or $6 \mathrm{~mm}$ cast-in steel rods, plus reference samples with no rod. The cement pastes were cast into thin silicon moulds, resulting in cylinders with diameter $10 \mathrm{~mm}$ and height about $12 \mathrm{~mm}$ (Fig. 1). The small sample size was selected to minimize temperature gradients and external restraint during hardening. The newly cast samples were stored in small, sealed glass containers 


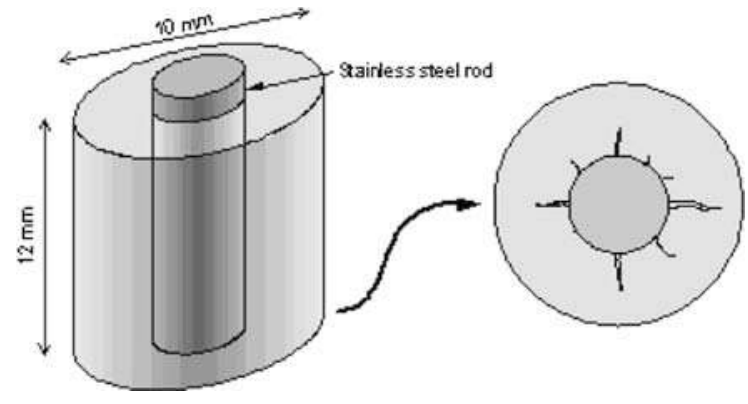

Fig. 1 Geometry of cement paste samples. The stainless-steel rod, of $1.5,3$ or $6 \mathrm{~mm}$ diameter, is cast longitudinally in the center of the sample

and kept for 1 month in a temperature controlled box at $32 \pm 0.2^{\circ} \mathrm{C}$. During hardening, the cement paste might crack due to the stress caused by the restraint that is induced by the steel rod [21]. Three different diameters of steel rods were used, since cracking may only be initiated beyond a certain minimum size of the inclusion [14]. Dimensions of the steel rods were chosen to be comparable with the maximum aggregate size of typical ultra-high-performance concrete. Steel was preferred to rock because the mechanical properties and surface characteristic of steel are well defined and reproducible.

Gallium is a silvery white metal with a melting point of $29.76^{\circ} \mathrm{C}$. In this research, liquid gallium was intruded into the cracks of the cement paste specimens by applying an external pressure. An intrusion pressure of 1.6 MPa was used for the cement paste samples, which enables filling pores with a diameter larger than $1.2 \mu \mathrm{m}$ that are connected to the surface $[14,15]$. After 1 month of hardening in sealed conditions, the silicon moulds were removed and the cement-paste samples were embedded in liquid gallium within a few seconds. Subsequently, the gallium was intruded into the samples with glycerol as a pressure-transmitting medium (Fig. 2). After $10 \mathrm{~min}$, water at $22^{\circ} \mathrm{C}$ was poured around the intrusion unit, leading to solidification of the gallium within $5 \mathrm{~min}$. The gallium-intruded samples were cast into epoxy resin and ground and polished until the bottom surface of the cement paste was exposed. The polished surfaces of the impregnated samples were examined with an optical and a scanning electron microscope $[14,15]$.

\section{Experimental results}

\subsection{Material properties}

Elastic modulus and fracture energy as a function of hydration time at $20^{\circ} \mathrm{C}$ [8] were converted to $32^{\circ} \mathrm{C}$ with an Arrhenius maturity function [19, 20]. Figure 3 shows curve fittings of the measured material properties to be used in the numerical simulation. In addition, Fig. 3 also reports a curve fitting of the measured autogenous strain at $32^{\circ} \mathrm{C}$. The shrinkage was zeroed at $6 \mathrm{~h}$ as the first rapid shrinkage after setting time ( $3 \mathrm{~h})$ and before $6 \mathrm{~h}$ [14] was considered to be negligible in the stress calculation.

\subsection{Crack patterns}

All samples were first examined with the optical microscope. Samples where microcracks were
Fig. 2 Scheme of gallium intrusion, illustrating the 3-step process: 1 gallium is poured over the sample in a silicone container; 2 the silicone container is positioned in the intrusion unit and pressure is applied; 3 cold water is poured around the intrusion unit leading to solidification of the gallium

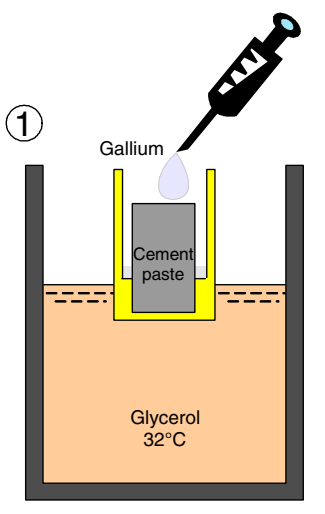

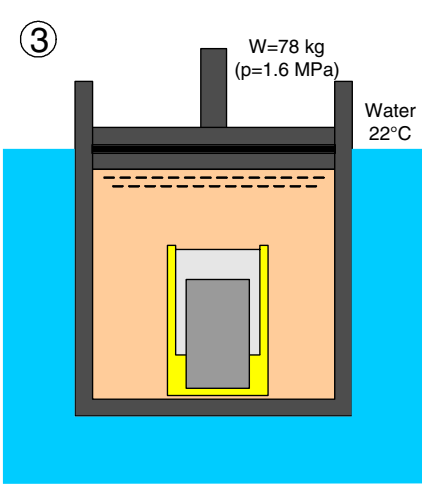

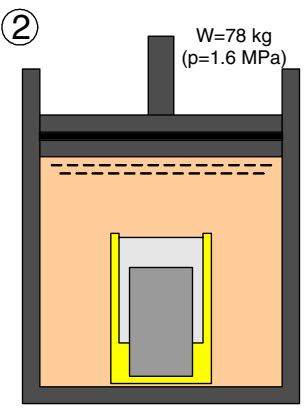


Fig. 3 Material properties as a function of time for the cement paste cured at $32^{\circ} \mathrm{C}$ : a critical stress intensity factor; b elastic modulus; c autogenous strain zeroed at $6 \mathrm{~h}$ (negative strain corresponds to shrinkage)

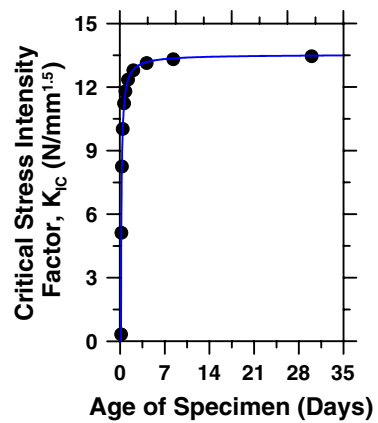

(a)

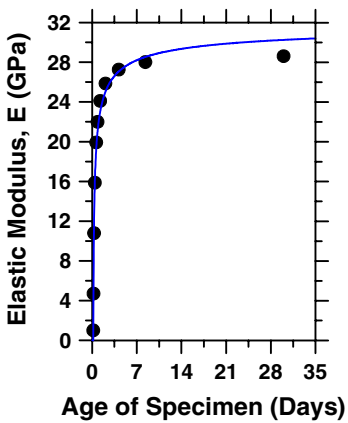

(b)

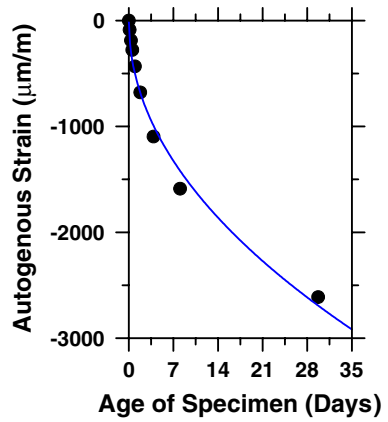

(c) observed were analyzed further by SEM, to confirm or exclude presence of gallium in the cracks. Microcracks were observed in samples with all dimensions of the steel rod, but in samples with $6-\mathrm{mm}$ rods the majority of the cracks propagated from the central rod to the outer surface. In the samples with smaller rods, smaller and shorter cracks were observed, which propagated from the central rod but did not reach the external surface. Table 1 shows a summary of the observed cracks.

Figure 4 shows a SEM image of a galliumintruded crack in a specimen with 6-mm steel rod. The crack runs through the whole thickness of the cement paste, from the steel rod, visible at the left side of Fig. 4, to the outer surface of the sample as seen at the right side of Fig. 4. The microcrack appears to have propagated along a relatively straight path from the restraining steel rod to the outer surface of the cement paste cylinder, with only limited branching in the center of the sample. During the intrusion process, gallium penetrated the crack from the outer surface and probably also from the bottom of the sample. A large air bubble present on the crack

Table 1 Summary of observed cracks in cylindrical samples of cement paste

\begin{tabular}{llll}
\hline $\begin{array}{l}\text { Rod } \\
\text { diameter } \\
(\mathrm{mm})\end{array}$ & $\begin{array}{l}\text { Samples } \\
\text { observed }\end{array}$ & $\begin{array}{l}\text { Samples } \\
\text { cracked }\end{array}$ & Observations \\
\hline 0 & 3 & 0 & $\begin{array}{l}\text { No cracks } \\
\text { Multiple short radial } \\
\text { cracks around rod } \\
1.5\end{array}$ \\
3 & 2 & 1 & $\begin{array}{r}\text { Multiple short radial } \\
\text { cracks around rod } \\
\text { Single through crack }\end{array}$ \\
6 & 3 & 2 & \\
\hline
\end{tabular}

Only gallium-intruded cracks are considered path, about $150 \mu \mathrm{m}$ in diameter, was also intruded by the liquid gallium. Image analysis performed on Fig. 4 reveals that the crack width varies from $11 \mu \mathrm{m}$ at the interface to about $25 \mu \mathrm{m}$ at the external surface of the paste cylinder.

\section{Modelling}

\subsection{Linear elastic analysis}

As a first approximation the highest stress developed in the samples can be estimated by considering the cement paste and steel rod as a 'shrink-fit' problem, where the steel rod is assumed to be incompressible [9, 22]. Initially, it will also be assumed that the cement paste behaves elastically. We can begin by removing the internal ring and calculating the free shrinkage displacement $\left(U_{F S}\right)$ at the inner surface of the paste ring [22]:

$\left.U\right|_{F S @ R_{I C}}=\varepsilon_{S H} \cdot R_{I C}$

where $\varepsilon_{S H}[\mathrm{~m} / \mathrm{m}]$ is the free shrinkage (negative in sign) and $R_{I C}[\mathrm{~m}]$ is the inner radius of the cement paste. We assume that the steel provides a pressure to the cement paste to counteract this displacement. The following formula relates pressure to displacement [23]:

$\left.U\right|_{p @ R_{I C}}=\frac{p}{E} \frac{R_{I C}^{2}}{R_{I C}\left(R_{O C}^{2}-R_{I C}^{2}\right)}\left[(1+v) R_{O C}^{2}+(1-v) R_{I C}^{2}\right]$

where $p[\mathrm{~Pa}]$ is the pressure at the interface, $E[\mathrm{~Pa}]$ is the elastic modulus of the paste, $R_{O C}[\mathrm{~m}]$ is the outer radius of the paste, and $v[-]$ is Poisson's ratio of the paste, assumed equal to 0.2 in this calculation. Since 


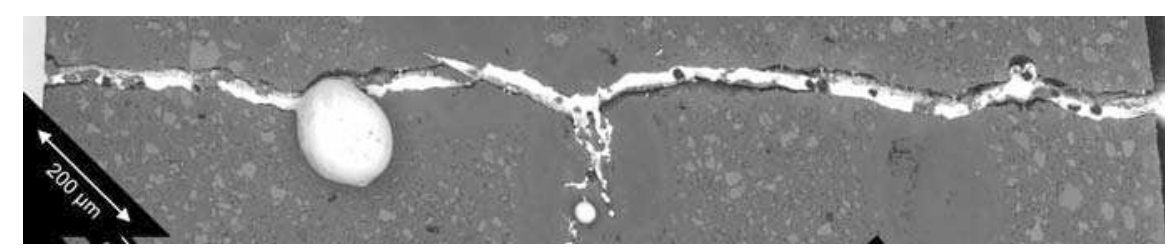

Fig. 4 Scanning electron microscope image of a crack running through a sample with a 6-mm steel rod. The steel rod (light grey) is seen at the left, solid gallium (white) fills a microcrack, while cement paste appears dark grey

the steel ring is assumed incompressible, the displacement at the inner surface of the cement paste can be computed as:

$$
\left.U\right|_{F S @ R_{I C}}+\left.U\right|_{p @ R_{I C}}=0
$$

Inserting Eqs. 1 and 2 into Eq. 3, an expression for the internal pressure that develops between steel and cement paste is obtained. This pressure can be related to the highest tensile stress that develops (at $r=R_{I C}$ ) in the tangential direction of the ring:

$\left.\sigma_{\theta}\right|_{R_{I C}}=p \frac{R_{O C}^{2}+R_{I C}^{2}}{R_{O C}^{2}-R_{I C}^{2}}$

Finally, Eq. 5 is derived, which can be used to compare the stresses that develop in the specimens with steel rods of different dimensions. The left hand side of the equation refers to the residual stress that develops and will be called the 'stress developed term'.

$\frac{\sigma_{\theta}}{\varepsilon_{S H} E}=\frac{\left(\frac{R_{O C}}{R_{I C}}\right)^{2}+1}{\left[\left(\frac{R_{O C}}{R_{I C}}\right)^{2}+1\right]+v\left[\left(\frac{R_{O C}}{R_{I C}}\right)^{2}-1\right]}$

The specimens studied in this paper vary in the value of $R_{O C} / R_{I C}$ : the $1.5-\mathrm{mm}$ steel rod specimen has a $R_{O C} / R_{I C}$ of 6.7 , the $3-\mathrm{mm}$ steel rod specimen has a $R_{O C} / R_{I C}$ of 3.3, and the 6-mm steel rod specimen has a $R_{O C} / R_{I C}$ of 1.7. Equation 5 is plotted in Fig. 5a. As the thickness of the wall of cement paste increases, i.e., as the diameter of the steel rod decreases from $6 \mathrm{~mm}$ to $3 \mathrm{~mm}$ to $1.5 \mathrm{~mm}$, the maximum developed stress (i.e., the stress at $r=R_{I C}$ ) diminishes. The stresses for the 6-mm rod are approximately $10 \%$ higher than for the 3-mm rod and 13\% higher than for the $1.5-\mathrm{mm}$ rod. This illustrates that the specimens with a thinner paste wall develop higher stresses under the same shrinkage conditions [9].

In addition to looking at the stresses that develop, it is possible to apply linear elastic fracture mechanics to analyze the effect of specimen geometry on the stress that can be resisted. The stress that can be resisted is shown on the left hand side of Eq. 6 and plotted in Fig. 5b:

$\frac{\sigma_{\theta}}{\sqrt{G_{I C} E}}=\frac{1}{f\left(\frac{a_{0}}{R_{O C}-R_{I C}}\right) \sqrt{\pi a_{0}}}$

where $G_{I C}[\mathrm{~N} / \mathrm{m}]$ is the critical fracture energy, $a_{O}[\mathrm{~m}]$ is the initial crack length, and $f\left(a_{O} /\left(R_{O C}-R_{I C}\right)\right)$ is a function that depends on the geometry of the specimen [24]. The initial crack length (flaw size) is generally estimated to be proportional to the largest particle in the system. For a cement paste, the flaw can be expected to be the size of the largest cement grain or slightly larger [24]. As shown in Fig. 5b, specimens with a thicker wall of cement paste are generally more resistant to cracking. In particular, when the flaw size is $100 \mu \mathrm{m}$, the $3-\mathrm{mm}$ rod specimen is $9 \%$ more resistant to cracking and the $1.5-\mathrm{mm}$ rod specimen is $15 \%$ more resistant to cracking than the 6-mm rod specimen. This geometry dependence increases with the initial flaw size.

As the wall thickness of the cement paste decreases (i.e., the rod becomes larger) the stress that develops increases (Eq. 5) and the stress that can be resisted decreases (Eq. 6) [25]. This corresponds with the experimental observation that the specimens with a thinner cement paste wall are more likely to crack (see Sect. 3.2). To compare the stress development with the stresses that can be resisted, Eqs. 5 and 6 can be compared. If the stress from Eq. 5 is substituted into Eq. 6 and the critical stress intensity factor $\left(K_{I C}\right)$ is used to replace the square root of the product of fracture energy $\left(G_{I C}\right)$ and elastic modulus $(E)$, the curves shown in Fig. 6 are obtained. This analysis assumes a linear elastic fracture mechanics failure (LEFM) criterion. LEFM is appropriate for cement paste systems since cement paste is relatively brittle. In Fig. 6, the y-axis represents the values of material properties (i.e., the product of shrinkage and 

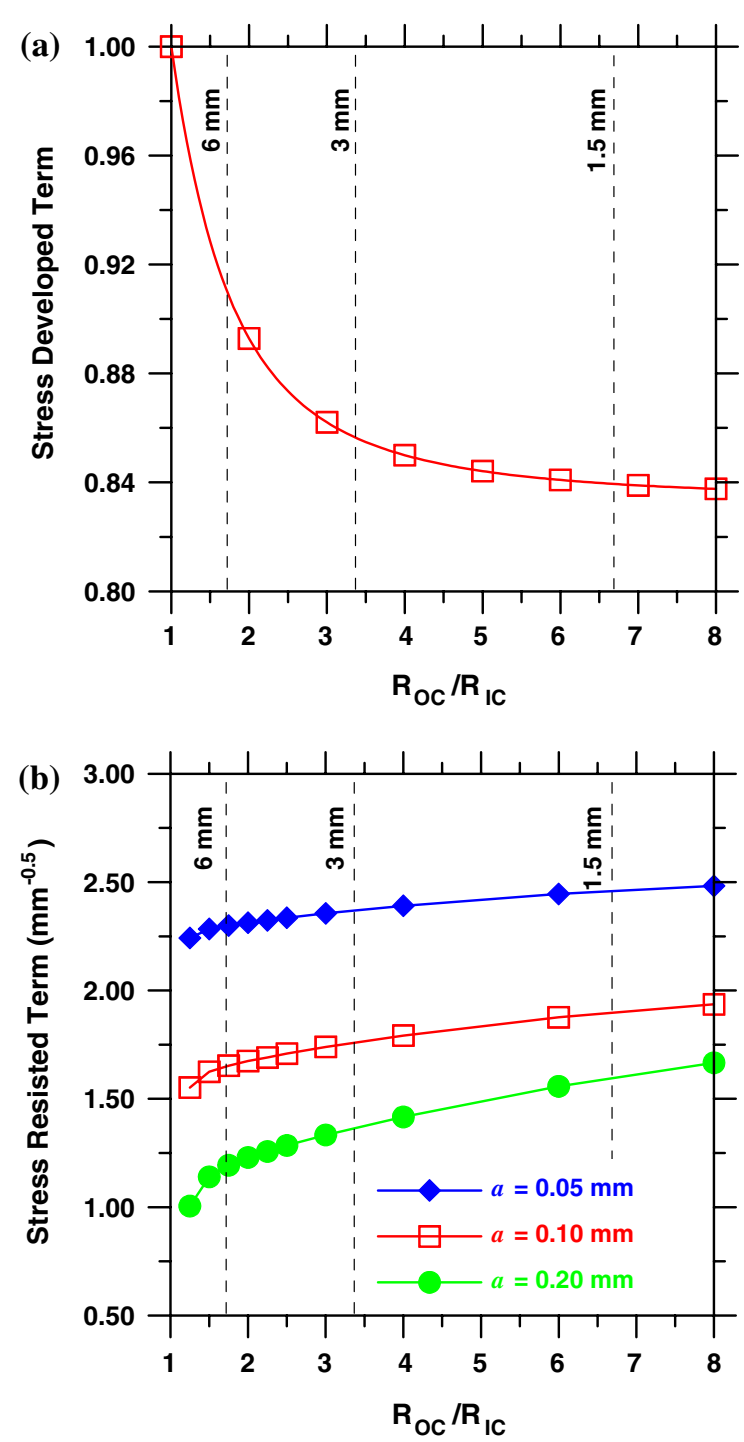

Fig. 5 Influence of cement paste wall thickness on (a) a term describing the stress that develops (Eq. 5) and (b) a term describing the stress that can be resisted before crack growth occurs (Eq. 6)

E modulus divided by the critical stress intensity factor) at the time of failure while the $\mathrm{x}$-axis represents the crack length $(a)$ at the time of failure. This forms a 'failure envelope' that can be used to describe the material behaviour.

In Fig. 6 an interesting difference is observed between specimens with a small wall thickness and specimens with larger wall thickness. The specimens with smaller wall thickness have what is commonly referred to as positive specimen geometry. This means that propagation of the crack results in specimen failure. In other words, once a crack of sufficient size forms at the interface between the steel rod and the cement paste and the stress is high enough to cause the crack to grow, the crack propagates all the way through the cement paste, reaching the outer surface. However, in specimens with larger wall thickness, cracks are able to grow in a semi-stable fashion; this is frequently referred to as a negative geometry where the crack driving energy actually decreases with crack growth. This can be illustrated by considering a specimen where an initial $200 \mu \mathrm{m}$ flaw is assumed to exist, approximately twice the size of a large cement particle (Fig. 6, dotted line). A specimen with a $R_{O C} / R_{I C}$ of 1.7 is stable until the product of the driving force $\left(\varepsilon_{S H} E / K_{I C}\right)$ reaches a value of 1.4; at this time the crack propagates through the specimen. A specimen with a $R_{O C} / R_{I C}$ of 6 has a negative specimen geometry and the crack growth is only unstable for a short period (until the crack is $310 \mu \mathrm{m})$. As the crack grows larger its growth is stable again and only grows as the driving force $\left(\varepsilon_{S H} E / K_{I C}\right)$ increases (i.e., the sample continues to shrink). However in the large wall specimen the crack will not propagate in an unstable fashion to the outer edge.

It should be noted that, when a LEFM failure criterion is applied, the transition from a positive geometry to a geometry that allows a stable crack growth occurs for specimens that are slightly thicker than $R_{O C} / R_{I C}$ of 4.0. If a non-linear failure criterion is used, this transition would be expected to occur with a smaller wall thickness. For example, for concrete it occurs at $R_{O C} / R_{I C}$ of about 2.0 [22].

\subsection{Analysis with time-dependent materials properties and creep}

While the previous section has illustrated basic trends, in the following section the effect of time dependent material properties and creep will be taken into consideration.

It should be noted that the steel rod is considered as infinitely stiff in the following calculations. This approximation leads to an overestimation of the stresses not higher than $8 \%$, estimated with the elastic solution and considering a fully hardened cement paste. Taking into account the low initial modulus of the cement paste and the effect of creep, the errors caused by this assumption should be negligible. 
Fig. 6 An illustration of the failure envelope for shrinkage cracking. The ordinate is the product of shrinkage, elastic modulus, and inverse of the critical stress intensity factor and is expressed in $1 / \operatorname{sqrt}(\mathrm{mm})$ units. Specimens below and to the left of the failure envelope do not fail, while the line denotes a condition where crack growth can occur

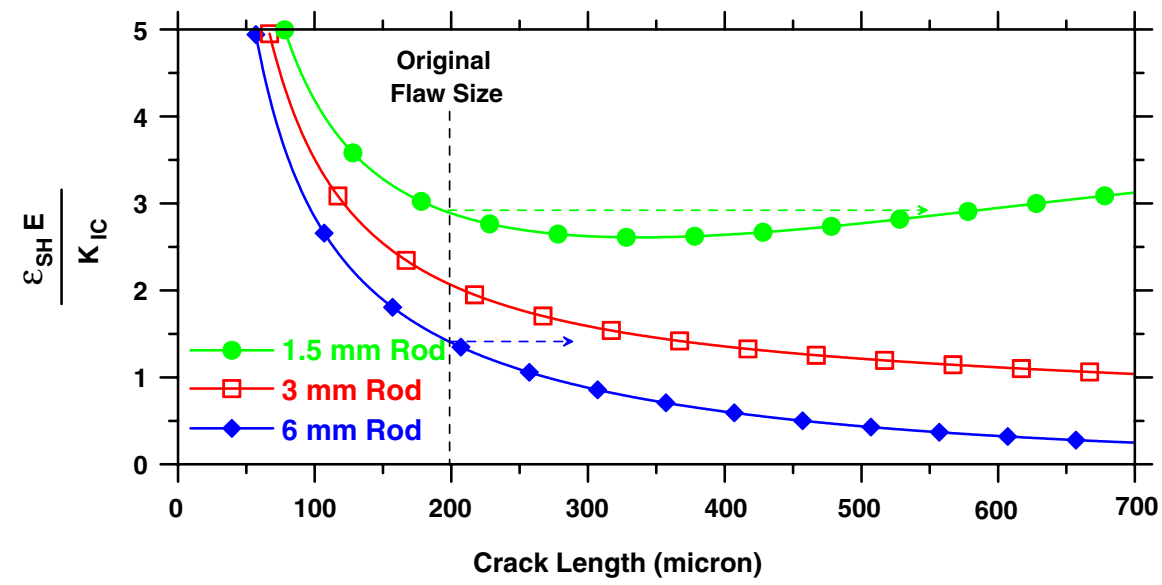

In the previous section and in previous work [16, 17], a simplified calculation of the stresses arising in the cement paste was performed. The specimen was considered as a thick-walled cylinder subjected to an inner pressure and the stresses were calculated with a simple formula, developed in [9]. In the following, both elastic modulus growing in time and creep of the cement paste will be taken into account. The modelling strategy and all the numerical details are explained in [22], to which the reader is referred.

The radial and tangential stresses, respectively $\sigma_{r}$ and $\sigma_{\theta}(\mathrm{Pa})$, at time $t[\mathrm{~s}]$ and at a radial distance $r\left(R_{O C} \geq r>R_{I C}\right)$ from the centre of the steel rod can be written as:

$$
\begin{aligned}
& \sigma_{r}(r, t)=\int_{0}^{t} A(\xi)\left(1-\frac{R_{O C}^{2}}{r^{2}}\right) d \xi \\
& \sigma_{\theta}(r, t)=\int_{0}^{t} A(\xi)\left(1+\frac{R_{O C}^{2}}{r^{2}}\right) d \xi
\end{aligned}
$$

where $R_{O C}=5 \mathrm{~mm}$ is the outer radius of the cement paste cylinder and $A(\mathrm{~Pa} / \mathrm{s})$ is a time-dependent parameter that can be calculated by solving numerically the following equation:

$$
\begin{aligned}
& \int_{0}^{t} C(t, \xi)\left[(1-v)+(1-v) \frac{R_{O C}^{2}}{R_{I C}^{2}}\right] A(\xi) d \xi+\varepsilon_{S H}(t) \\
& \quad=0
\end{aligned}
$$

where $v=0.2$ is the Poisson's ratio of the cement paste, considered constant in time, $R_{I C}$ is the radius of the steel rod, either $0.75,1.5$ or $3 \mathrm{~mm}, \varepsilon_{S H}(\mathrm{~m} / \mathrm{m})$ is the shrinkage of the cement paste, and $C(1 / \mathrm{Pa})$ is the aging compliance of the cement paste, which is defined as:

$C(t, \xi)=\frac{1}{E(\xi)}+\frac{\phi(t, \xi)}{E_{28}}$

being $E(\xi)(\mathrm{Pa})$ the elastic modulus at any time $\xi, E_{28}$ the compressive elastic modulus at 28 days, and $\phi(t, \xi)$ the creep coefficient as proposed by Müller [26]. It should be noted that this creep model was developed for concrete, but as a first approximation it is reasonable to assume that the creep coefficient for cement paste would have a similar form.

As input for the elastic modulus, fracture energy and the autogenous strain, the curve fittings shown in Fig. 3 were employed.

Figure 7 shows the stress distribution in the cement paste wall at an age of 28 days, assuming that the specimen does not crack before that age. The stresses decrease as a function of $1 / r^{2}$ for all specimens. It is interesting to note that the $6-\mathrm{mm}$ rod specimen (i.e., the specimen with smallest wall thickness) has more uniform stress throughout the specimen: $15.7 \mathrm{MPa}$ at the steel-paste interface and $8.3 \mathrm{MPa}$ at the outer edge of the paste. This leads to a higher probability for unstable crack propagation and through cracking. On the contrary, the sample with the smallest rod has a similar stress level near the rod (14.6 MPa), but a much lower stress level at the outer edge of the paste $(0.6 \mathrm{MPa})$. The stress distribution across the cement paste section controls the crack growth.

Moon et al. [11] showed that the highest stresses are released if stable cracking is permitted. In 
Fig. 7 Tangential stress distribution along the radial direction at 28 days illustrating the differences in stress distribution for the different sized rods

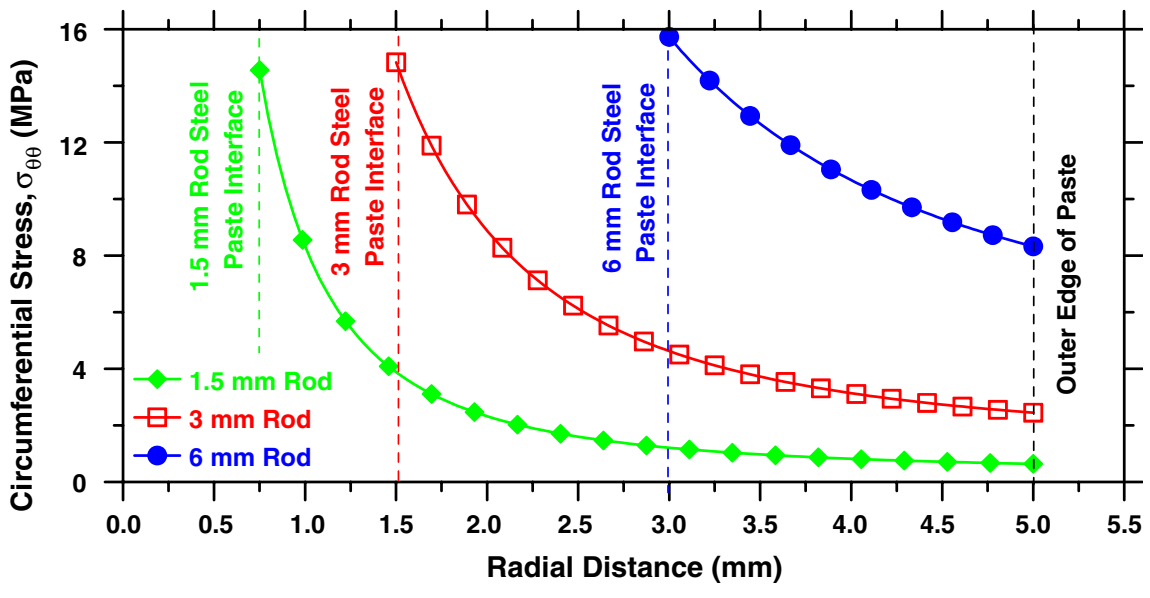

specimens with small steel rods, cracking would occur very close to the steel-paste interface, greatly reducing the maximum stress; however this crack would not grow very far. For example, in the $1.5-\mathrm{mm}$ rod specimen (with $R_{O C} / R_{I C}=6.6$ ), the crack would grow in a stable fashion for a length on the order of $\mathrm{mm}$ without causing the specimen to fail. As the crack grows in a stable mode the stress distribution in the specimen changes dramatically. In fact, the maximum stress in the specimen is reduced from 14.6 MPa at the interface to approximately $1 / 5$ of that value only $1 \mathrm{~mm}$ away. This greatly reduces the stored energy and the potential for the crack to grow unstably across the specimen.

Figure 8a illustrates the maximum elastic stress development, the maximum stress development considering creep, and the strength for the specimen with a 6-mm rod. The strength corresponds to the fracture resistance calculated based on a LEFM failure criterion. According to the calculations, creep reduces substantially the stresses that develop in the specimen. The stress would exceed the fracture resistance at approximately 18 days which would correspond to through cracking.

Figure $8 \mathrm{~b}$ compares the stress that develops in the specimens with different geometry (considering creep) with their fracture resistance [22]. It can be seen that the thin-wall specimen $\left(R_{O C} / R_{I C}=1.5\right)$ is predicted to crack, while the thickest-wall specimen ( $R_{O C} / R_{I C}=6$, approximately) shows a significant factor of safety, about $30 \%$. The intermediate geometry would be close to failure. It should be noted however that the intersection of these lines is based on a deterministic approach for the prediction of cracking, while recent investigations have shown that slight variations in materials properties may influence the age of cracking substantially [5, 27, 28].
Fig. 8 Maximum stress and strength development in time of cement paste samples with steel rod: a comparison of stresses calculated with and without creep for one specimen and b maximum stress and strength for all specimens considering creep. The strength term plotted in the graphs corresponds to the stress resisted term calculated with Eq. 6
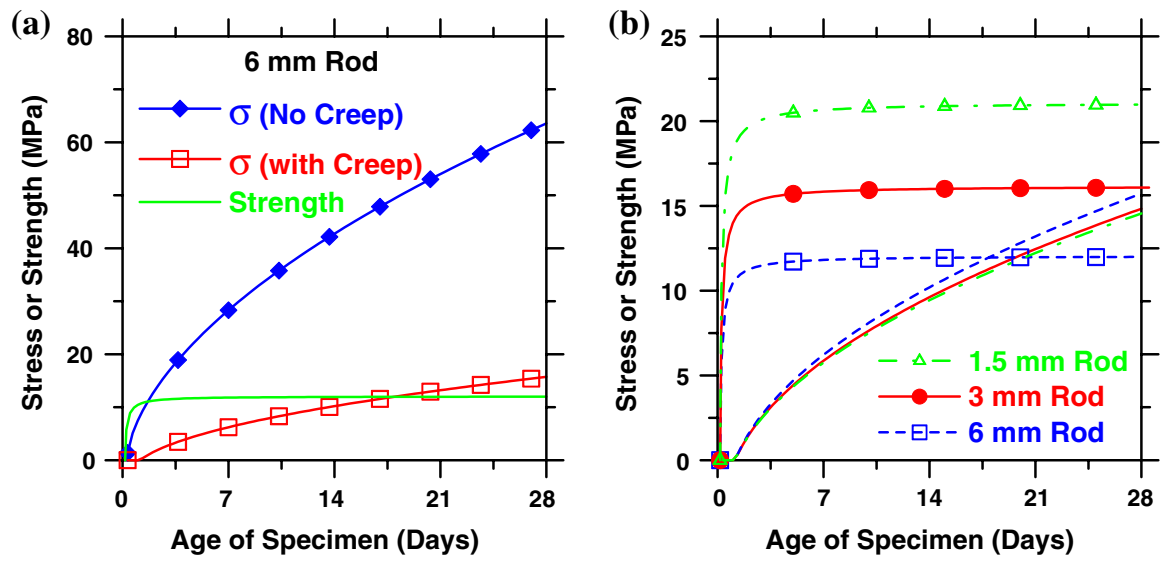


\section{Discussion}

In this section the numerical results of the previous sections will be compared with the experimental results.

The first observation concerns the presence and the morphology of cracks in the samples with steel rods of different dimensions. A summary of the observed cracks in the cement paste was shown in Table 1. The results of Table 1 are similar to the conclusions of the numerical simulation. The majority of the samples with large steel rod ( 2 out of 3 ) failed with a single crack propagating through the cement paste (see Fig. 4). This experimental result is agreement with numerical results presented in Figs. 6 and 8. On the other hand, only 2 out of 5 cylinders with smaller rods showed gallium-intruded cracks. Both samples showed two distinct narrow cracks that started at the steel rod and propagated along the radial direction for 1-2 mm. A detail of a sample with $1.5-\mathrm{mm}$ steel rod is shown in Fig. 9. Two narrow dark cracks are visible in the picture. The cracks stop after about $1 \mathrm{~mm}$ from the surface of the steel rod. This result is in good agreement with Fig. 6, where stable crack growth was calculated for this specimen.

It is possible to extend the numerical simulation performed in Sect. 4.2 to calculate the crack width of the crack shown in Fig. 4. Similar calculations have

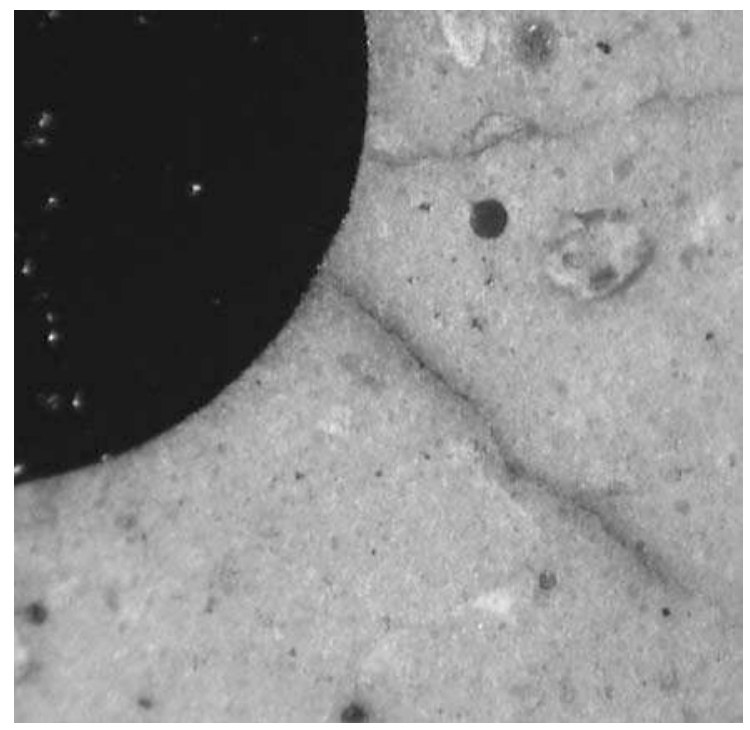

Fig. 9 Optical microscope image of a sample with 1.5-mm steel rod, showing gallium-intruded microcracks. The picture is about $1.7 \mathrm{~mm}$ across already been performed to calculate the crack width in the ring test [29]. To perform this calculation on the specimens with embedded steel rods, it is assumed that once the microcrack snaps open, all the elastic strain stored in the cement paste is completely released. The cement paste has no adhesion to the steel rod and it slides freely recovering all the strain. Moreover, since cracking occurs at 18 days according to the results in Fig. 8, the formed microcrack is further widened by the autogenous shrinkage that occurs between 18 and 30 days (see Fig. 3). In a previous paper [16], the crack width had been calculated based on a complete recovery of all the autogenous shrinkage of the paste. In the following calculation, the fact that part of the eigenstresses developing in the paste is relaxed in time will be taken into account.

When the crack opens at 18 days, a strain of about $410 \mu \mathrm{m} / \mathrm{m}$ is released at the interface of the rod, while a strain of about $220 \mu \mathrm{m} / \mathrm{m}$ is released at the external surface of the paste cylinder. These values have been calculated dividing the tangential stress at 18 days (Fig. 8) by the elastic modulus of the paste at the same age (Fig. 3); since the stresses at the interface are larger, also the recovered strain is larger. The stress in the tangential direction was calculated taking into account both the time-dependent development of the elastic modulus of the cement paste and the relaxation of the internal stresses due to creep. To this strain, about $200 \mu \mathrm{m} / \mathrm{m}$ have to be added, which correspond to the autogenous shrinkage occurring between 18 and 30 days, when the sample was finally intruded with gallium. The crack width at each extremity of the crack is found multiplying this total strain either by the inner or by the outer circumference of the cement paste.

The calculated crack width varies from $11 \mu \mathrm{m}$ at the steel-paste interface to $13 \mu \mathrm{m}$ at the free surface. As mentioned in Sect. 3.2, the width of the microcrack shown in Fig. 4 varied from $11 \mu \mathrm{m}$ at the interface of the steel rod to about $25 \mu \mathrm{m}$ at the external surface of the paste cylinder. This is a very good agreement, considering all the uncertainties involved in the numerical calculation, especially about the material properties of the cement paste.

According to these results, adhesion of the cement paste to the surface of the steel rod does not appear to have reduced the crack width at the interface. A 
similar result was also obtained in numerical simulations of internal microcracking in concrete [12].

\section{Conclusions}

The gallium-intrusion technique described in this paper enables investigation of microcracks formed in specimens undergoing autogenous volume change when this volume change is restrained. With this technique it is possible to distinguish cracks present in the sample at the moment of gallium impregnation from cracks caused by the subsequent sample preparation. A convenient technique for crack detection and analysis is optical microscopy combined with SEM analysis of the microcracks to reveal presence of gallium.

In the cement pastes that were studied, microcracking depended both on the autogenous shrinkage of the cement paste and on the dimension of the restraining steel rod. Through cracks were observed in samples with larger steel rods (i.e., smaller paste wall thicknesses) and higher autogenous shrinkage. Crack width was determined by image analysis on SEM micrographs.

Numerical simulation of the specimens, taking into account the nonlinear and time-dependent behaviour of the cement paste, showed that a strength-based failure criterion may not be fully sufficient to describe failure. On the contrary, a fracture-based failure criterion clearly illustrates the influence of specimen geometry on cracking. Thin wall specimens have a so-called positive fracture geometry which results in the unstable propagation of a crack when the critical stress level is reached. Thick walled specimens however have a negative geometry which can result in stable crack growth. This stable crack growth greatly reduces the high driving stress level near the paste-rod interface, thereby reducing or preventing the potential for through cracking.

Crack patterns, length and width of microcracks observed with the gallium-intrusion technique showed good agreement with the results of the nonlinear numerical simulation.

Based on the results of this combined experimental and numerical study on model systems of cement paste with embedded steel rods, it appears that the available models for the behaviour of cement paste at early ages are able to predict the internal stress development, microcracking, and through cracking for a layer of paste around a rigid inclusion like an aggregate.

Acknowledgements The work described in this paper was carried out thanks to kind support from the "Ingeborg og Leo Dannins Legat for Videnskabelig Forskning" (Ingeborg and Leo Dannin's grant for Scientific Research).

\section{References}

1. Jensen OM, Hansen PF (2001) Autogenous deformation and RH-change in perspective. Cement Concr Res 31(12):1859-1865. doi:10.1016/S0008-8846(01)00501-4

2. Pigeon M, Toma G, Delagrave A, Bissonette B, Marchand J, Prince JC (2000) Equipment for the analysis of the behaviour of concrete under restrained shrinkage at early ages. Mag Concr Res 52(4):297-302

3. Igarashi S, Bentur A, Kovler K (2000) Autogenous shrinkage and induced restraining stresses in high-strength concretes. Cement Concr Res 30(11):1701-1707. doi: 10.1016/S0008-8846(00)00399-9

4. Lura P, van Breugel K, Maruyama I (2001) Effect of curing temperature and type of cement on early-age shrinkage of high-performance concrete. Cement Concr Res 31(12):1867-1872. doi:10.1016/S0008-8846(01)00601-9

5. Loser R, Leemann A (2009) Shrinkage and restrained shrinkage cracking of self-compacting concrete compared to conventionally vibrated concrete. Mater Struct 42 (in press). doi:10.1617/s11527-008-9367-9

6. Mindess S, Diamond S (1982) The cracking and fracture of mortar. Mater Struct 15(2):107-113

7. Lawler JS, Shah SP (2004) Fracture processes of quasibrittle materials studied with digital image correlation. In: Recent advances in experimental mechanics: in honor of I.M. Daniel, part 4, pp 335-344

8. Dela BF (2000) Eigenstresses in hardening concrete. Ph.D. thesis, Department of Structural Engineering and Materials, Technical University of Denmark, Lyngby, Denmark

9. Pease B, Neuwald A, Weiss WJ (2003) 'The influence of aggregates on early age cracking in cementitious systems', Celebrating concrete: role of concrete in sustainable development, International symposium dedicated to Prof. S. Shah, Northwestern University, September 2003, pp 329-338

10. Garboczi EJ (1997) Stress, displacement, and expansive cracking around a single spherical aggregate under different expansive conditions. Cement Concr Res 27(4):495500. doi:10.1016/S0008-8846(97)00029-X

11. Moon JH, Couch JB, Weiss WJ (2006) Preliminary numerical assessment of microcracking caused by autogenous shrinkage in a heterogeneous system. In: Measuring, monitoring and modeling concrete properties, international symposium dedicated to Prof. S.P. Shah, ECF-16, Springer, Part III, pp 317-323

12. Moon JH, Rajabipour F, Pease B, Weiss J (2005) Autogenous shrinkage, residual stress, and cracking in cementitious composites: the influence of internal and 
external restraint. In: Person B, Nilsson (eds) Proceedings of the 4th international seminar on self-desiccation and its importance in concrete technology, 20 June 2005 (Gaithersburg, MD), pp 1-20

13. Jensen OM (2003, April) Micro-crack detection in highperformance cementitious materials. Report, Tokyo Institute of Technology

14. Lura P, Jensen OM (2005) Micro-crack detection in highperformance cementitious materials based on gallium intrusion. Technical report, Technical University of Denmark, Lyngby, Denmark, 28 pp

15. Lura P, Ye G, Tanaka K, Jensen OM (2005) Microcrack detection in high-performance cementitious materials. Proceedings of 4th international seminar on self-desiccation and its importance in concrete technology, Gaithersburg. MD 20(June), pp 165-178

16. Lura P, Ye G, Tanaka K, Jensen OM (2005) Identification of microcracks caused by autogenous shrinkage. In: Proceedings of international workshop on material science in 21 st century for the construction industry - durability, repair and recycling of concrete structures, 11 August 2005 (Sapporo, Japan), pp 13-20

17. Lura P, Jensen OM, Weiss J (2007) Detection and analysis of microcracks in high-performance cementitious materials. Advances in construction materials, Symposium in Honor of H.W. Reinhardt, 23-25 July 2007 (Stuttgart, Germany). Springer, Berlin, pp 607-614

18. Jensen OM, Hansen PF (1995) A dilatometer for measuring autogenous deformation in hardening Portland cement paste. Mater Struct 28(181):406-409. doi:10.1007/ BF02473076

19. Hansen PF, Pedersen EJ (1977) Measuring instrument for the control of concrete hardening (in Danish). Nord Betong 21-25

20. Jensen OM, Hansen PF (1999) Influence of temperature on autogenous deformation and relative humidity change in hardening cement paste. Cement Concr Res 29(4):567575. doi:10.1016/S0008-8846(99)00021-6

21. Dela BF, Stang H (2000) Two-dimensional analysis of crack formation around aggregates in high-shrinkage cement paste. Eng Fract Mech 65(2):149-164. doi: 10.1016/S0013-7944(99)00113-7

22. Weiss WJ, Yang W, Shah SP (2000) Influence of specimen size/geometry on shrinkage cracking of rings. J Eng Mech 126(1):93-101. doi:10.1061/(ASCE)0733-9399(2000)126: $1(93)$

23. Weiss WJ (1999) Prediction of early age cracking in thick concrete structures. $\mathrm{PhD}$ thesis, Northwestern University, Evanston, IL

24. Weiss WJ, Yang W, Shah SP (1998) Shrinkage cracking of restrained concrete slabs. J Eng Mech 124(7):765-774. doi: 10.1061/(ASCE)0733-9399(1998)124:7(765)

25. Wu XR, Carlson AJ (1991) Weight functions and stress intensity factors. Pergamon, Tarrytown

26. Müller HS (1992) New prediction models for shrinkage and creep of concrete. In: Fu CC, Daye MA (eds) Creep and shrinkage of concrete: effect of materials and environment, SP-135. ACI, Detroit, pp 1-19

27. Radlinska A, Weiss WJ (2006) Quantifying variability in assessing the risk of early-age cracking in restrained concrete elements. Proceedings of international symposium on 8th Brittle Matrix Conference, Warsaw, Poland, October 23-25, 2006, pp 331-342

28. Radlinska A, Pease B, Weiss J (2007) A preliminary numerical investigation on the influence of material variability in the early-age cracking behavior of restrained concrete. Mater Struct 40(4):375-386. doi:10.1617/ s11527-006-9118-8

29. Shah HR, Weiss J (2006) Quantifying shrinkage cracking in fiber reinforced concrete using the ring test. Mater Struct 39(9):887-899. doi:10.1617/s11527-006-9089-9 